\title{
Pleural Well Differentiated Papillary Mesothelioma
}

National Cancer Institute

\section{Source}

National Cancer Institute. Pleural Well Differentiated Papillary Mesothelioma. NCI

Thesaurus. Code C45660.

A rare, non-invasive, localized or multifocal neoplasm that arises from the pleura. It is characterized by the presence of papillae with myxoid fibrovascular cores, lined by a single layer of mesothelial cells. The clinical course is usually indolent. 